\title{
Integrated active fire retrievals and biomass burning emissions using complementary near-coincident ground, airborne and spaceborne sensor data
}

\author{
Wilfrid Schroeder ${ }^{\mathrm{a}, *}$, Evan Ellicott ${ }^{\mathrm{a}}$, Charles Ichoku ${ }^{\mathrm{b}}$, Luke Ellison ${ }^{\mathrm{b}, \mathrm{h}}$, Matthew B. Dickinson ${ }^{\mathrm{c}}$, \\ Roger D. Ottmar ${ }^{\mathrm{d}}$, Craig Clements ${ }^{\mathrm{e}}$, Dianne Hall ${ }^{\mathrm{e}}$, Vincent Ambrosia ${ }^{\mathrm{f}}$, Robert Kremens ${ }^{\mathrm{g}}$ \\ a Department of Geographical Sciences, University of Maryland, College Park, MD, United States \\ ${ }^{\mathrm{b}}$ NASA Goddard Space Flight Center, Greenbelt, MD, United States \\ c USDA Northern Research Station, Delaware, OH, United States \\ d USDA Pacific Northwest Research Station, Seattle, WA, United States \\ e San José State University, San José, CA, United States \\ ${ }^{\mathrm{f}}$ California State University, Monterey Bay, CA, United States \\ ${ }^{\mathrm{g}}$ Rochester Institute of Technology, Rochester, NY, United States \\ ${ }^{\mathrm{h}}$ Science Systems and Applications, Inc., Lanham, MD, United States
}

\section{A R T I C L E I N F O}

\section{Article history:}

Received 17 June 2013

Received in revised form 9 October 2013

Accepted 10 October 2013

Available online 4 November 2013

\section{Keywords:}

Biomass burning

Remote sensing

Airborne scanner

MODIS

GOES

Fire radiative power

Fire emissions

\begin{abstract}
A B S T R A C T
Ground, airborne and spaceborne data were collected for a 450 ha prescribed fire implemented on 18 October 2011 at the Henry W. Coe State Park in California. The integration of various data elements allowed nearcoincident active fire retrievals to be estimated. The Autonomous Modular Sensor-Wildfire (AMS) airborne multispectral imaging system was used as a bridge between ground and spaceborne data sets providing highquality reference information to support satellite fire retrieval error analyses and fire emissions estimates. We found excellent agreement between peak fire radiant heat flux data $(<1 \%$ error) derived from near-coincident ground radiometers and AMS. Both MODIS and GOES imager active fire products were negatively influenced by the presence of thick smoke, which was misclassified as cloud by their algorithms, leading to the omission of fire pixels beneath the smoke, and resulting in the underestimation of their retrieved fire radiative power (FRP) values for the burn plot, compared to the reference airborne data. Agreement between airborne and spaceborne FRP data improved significantly after correction for omission errors and atmospheric attenuation, resulting in as low as 5\% difference between Aqua/MODIS and AMS. Use of in situ fuel and fire energy estimates in combination with a collection of AMS, MODIS, and GOES FRP retrievals provided a fuel consumption factor of $0.261 \mathrm{~kg} \mathrm{MJ}^{-1}$, total energy release of $14.5 \mathrm{e}+06 \mathrm{MJ}$, and total fuel consumption of $3.8 \mathrm{e}+06 \mathrm{~kg}$. Fire emissions were calculated using two separate techniques, resulting in as low as $15 \%$ difference for various species.
\end{abstract}

(c) 2013 Elsevier Inc. All rights reserved.

\section{Introduction}

Global biomass burning is a major source of aerosols and trace gases that are known to impact the physics of the atmosphere and therefore to influence the Earth's climate (Crutzen \& Andreae, 1990). Climate oscillations and feedbacks can induce large inter-annual variability in regional biomass burning activity creating wildfire-prone areas as a result of dryer and warmer climate conditions (Hoffmann, Schroeder, \& Jackson, 2003; Phillips et al., 2009; Westerling, Hidalgo, Cayan, \& Swetnam, 2006). Biomass burning is also a key disturbance factor at landscape and regional scales, often associated with rapid deterioration of air quality as well as long-lasting effects on surface properties

* Corresponding author at: Department of Geographical Sciences, University of Maryland, 2181 LeFrak Hall, College Park, MD 20742, United States. Tel.: +1 2023417763. E-mail address: wilfrid.schroeder@noaa.gov (W. Schroeder). including land cover change and runoff alteration (DeBell et al., 2004; Jaffe et al., 2004; McKenzie, Gedalof, Peterson, \& Mote, 2004; Moody, Martin, Haire, \& Kinner, 2007). Accurate characterization of biomass burning is therefore crucial to enable quantification of its impacts on local biomes and on regional and global climate feedbacks, as well as for the development of land management strategies to help prepare for wildland fires and to mitigate their effects.

Wildland fires create unsafe conditions for people, subject ground instrumentation to harsh conditions, and are diverse in their timing, duration, and geographical location and extent. These issues are commonly addressed with the use of airborne or spaceborne remote sensing data that capture the radiative component of the energy released during combustion (Dozier, 1981; Giglio, 2007; Kaufman, Justice, et al., 1998; Prins \& Menzel, 1992). Kaufman, Justice, et al. (1998) pioneered the retrieval of satellite-based fire radiative power (FRP) using an empirical approach based on brightness temperature 
data in the $4 \mu \mathrm{m}$ region. Wooster, Zhukov, and Oertel (2003) introduced an alternative FRP retrieval using a physical approach based on $4 \mu \mathrm{m}$ radiance data. Meanwhile, laboratory and small field plot data analyses quantified the relationship between the time-integrated FRP retrievals, or fire radiative energy (FRE), and fuel consumption (Freeborn et al., 2008; Ichoku, Martins, et al., 2008; Kremens, Dickinson, \& Bova, 2012; Wooster, Roberts, \& Perry, 2005).

The emission of a range of gas species and particulates from fire is traditionally related to fuel consumption through their emission factors (e.g., Andreae \& Merlet, 2001). However, emission factors found in the literature vary significantly depending on the experimental conditions, variables and assumptions used to derive them, resulting in a factor of 2-4 uncertainty (e.g., Kaiser et al., 2012). The new satellite fire characterization approach based on FRP has fostered the development of simplified fire emissions calculation methods based on the use of fewer variables and assumptions than the traditional approaches, hence showing great potential to reduce retrieval errors (Ellicott, Vermote, Giglio, \& Roberts, 2009; Ichoku, Giglio, Wooster, \& Remer, 2008; Ichoku \& Kaufman, 2005; Vermote et al., 2009).

The launch of the Moderate Resolution Imaging Spectroradiometer (MODIS) onboard the Earth Observing System Terra and Aqua satellites in 1999 and 2002, respectively, was a major step in the development of improved quantitative characterization of biomass burning (Justice et al., 2002). The MODIS sensors provided, for the first time, systematic global detection and characterization of active fires using FRP with negligible pixel saturation rates (Giglio, Descloitres, Justice, \& Kaufman, 2003; Kaufman, Justice, et al., 1998). Subsequently, fire retrievals similar to the routinely derived MODIS FRP were also developed for the operational Wildfire Automated Biomass Burning Algorithm (WF_ABBA) using coarser spatial resolution Geostationary Operational Environmental Satellite (GOES) imager data. However, a non-negligible pixel saturation rate of up to $10 \%$, which is dependent on fire and observation conditions, can negatively impact the GOES FRP retrievals (Pereira et al., 2009). Nonetheless, the higher observation frequency provided by geostationary platforms represents a major advantage, which can be exploited using the available saturation-free fire pixels (Xu, Wooster, Roberts, \& Freeborn, 2010). Other operational environmental monitoring satellite sensors including the Advanced Very High Resolution Radiometer (AVHRR) onboard the NOAA polar orbiter series may also be used to derive fire characterization data, although high pixel saturation rates undermine their application (Setzer \& Verstraete, 1994).

Airborne sensors have also been used extensively in support of fire management in the United States, and to a lesser extent in support of fire science studies in different geographic regions (Kaufman, Kleidman, \& King, 1998; King, Platnick, Moeller, Revercomb, \& Chu, 2003; Oertel et al., 2003; Riggan et al., 2004). Use of airborne platforms for quantitative fire imaging requires that sensors operating in the middle-infrared $(\approx 4 \mu \mathrm{m})$ spectral region have a high dynamic range because it is in this region that fires emit most of their radiation. These sensors must be able to resolve fires at spatial resolutions typically finer than $30 \mathrm{~m}$ and accommodate temperature fields ranging from $\sim 300 \mathrm{~K}$ background to flaming fronts reaching upwards of $1200 \mathrm{~K}$. Currently, no airborne system fulfills those fire imaging requirements although a few instruments show reasonable configurations (e.g., Ononye, Vodacek, \& Saber, 2007; Riggan et al., 2004). NASA's Autonomous Modular SensorWildfire (AMS) has been flown in support of fire science missions aboard both manned and unmanned aircraft (Ambrosia \& Hinkley, 2008). The sensor has a multi-spectral channel configuration covering the visible and infrared parts of the spectrum and a nominal saturation temperature of approximately $620 \mathrm{~K}$ at its middle-infrared $(\approx 3.75 \mu \mathrm{m})$ channel. The application of the AMS sensor over numerous fire imaging missions has successfully demonstrated its potential to both map and quantify biomass burning, generating fire retrievals at much higher spatial resolution compared to the available spaceborne active fire data sets (Peterson, Wung, Ichoku, Hyer, \& Ambrosia, 2013). Because of its high radiometric and geometric data quality, AMS can serve as a bridge instrument linking ground and spaceborne fire retrievals. As such, AMS qualifies as a standalone fire management data system as well as a science support tool with great potential for use in satellite fire data validation applications.

The objective of this study is to advance the use of complementary ground and airborne fire data sets in support of the development and validation of satellite-based active fire retrieval methods and emissions estimates. We build on a collective effort to map and characterize a prescribed fire near San José, California, during which near-coincident fire retrievals were generated using an array of ground plots, airborne imaging, and spaceborne polar-orbiting and geostationary sensor data. Active fire retrievals were derived first using near-coincident ground and airborne data over small ground control plots to develop robust airborne reference data. Then, FRP was estimated for the entire fire from airborne data, and the results compared with near-coincident spaceborne retrievals. Fire emissions estimates were calculated using two separate methods based on the FRE data derived from the integrated airborne and spaceborne FRP retrievals. We discuss the merits and limitations of the techniques tested and their potential application in support of quantitative biomass burning analyses.

\section{Data and methods}

The data set analyzed in this study arises from a prescribed fire implemented on 18 October 2011 by the Santa Clara Unit of the California Department of Forestry and Fire Protection (CAL FIRE) and California State Parks at the Henry W. Coe State Park, hereafter abbreviated as HCSP, located approximately $100 \mathrm{~km}$ southeast of San Francisco, California. The park is the largest state park in northern California, comprising $\sim 35,000$ ha of rugged terrain. The prescribed fire was implemented in a 450 ha plot composed of a mix of grassland, oak woodland, chaparral and ponderosa pine forest (Fig. 1).

Data collected in this study included fuel loading and consumption and ground-, aircraft-, and satellite-based fire radiation measurements. All data acquisition times are reported in Universal Time Coordinated (UTC). The local time at the HCSP site during the sampling period is equivalent to UTC-7 h.

\subsection{Ground fuel sampling}

Ground-level measurements of fuel loading, fuel consumption, and moisture content were collected from two $100 \times 200$-m (2 ha) blocks located next to ground fire sampling instruments (Section 2.2). A grass fuel component consisting of a non-native slender oat (Avena barbata) and a native blue wild rye (Elymus glaucus) was the primary fuel that carried the fire through these blocks. Fifteen pre- and fifteen post-burn clip plots $\left(1-\mathrm{m}^{2}\right)$ were established at 10 meter intervals along 3 grid lines spaced $20 \mathrm{~m}$ apart within the blocks. Fuel from within each clip plot was collected and separated into a grass or forb fuel types, oven dried, then weighed to determine pre- and post-burn loading. Consumption was calculated by subtracting the average pre-burn loading from average post-burn loading, for each set of plots. Five to ten 6-liter plastic bags of fuel moisture content samples representing the grass and forbs were collected immediately before each burn. The samples were weighed and oven dried at $70^{\circ} \mathrm{C}$ for $24 \mathrm{~h}$ to determine percent moisture content. Time limited the ability to establish fuel loading and consumption sampling sites in a forested or shrub area within the fire boundary. This would have represented a more complex fuel bed found within the fire perimeter with grass and forbs along with a dead woody and litter fuel component.

\subsection{Ground fire measurement}

Fire radiative power was estimated using nadir-viewing dual-band radiometers placed at $2.5 \mathrm{~m}$ above ground on steel tripods. Calibration and use of dual-band radiometers similar to the ones deployed in this experiment are described in Kremens et al. (2012). The middle infrared 

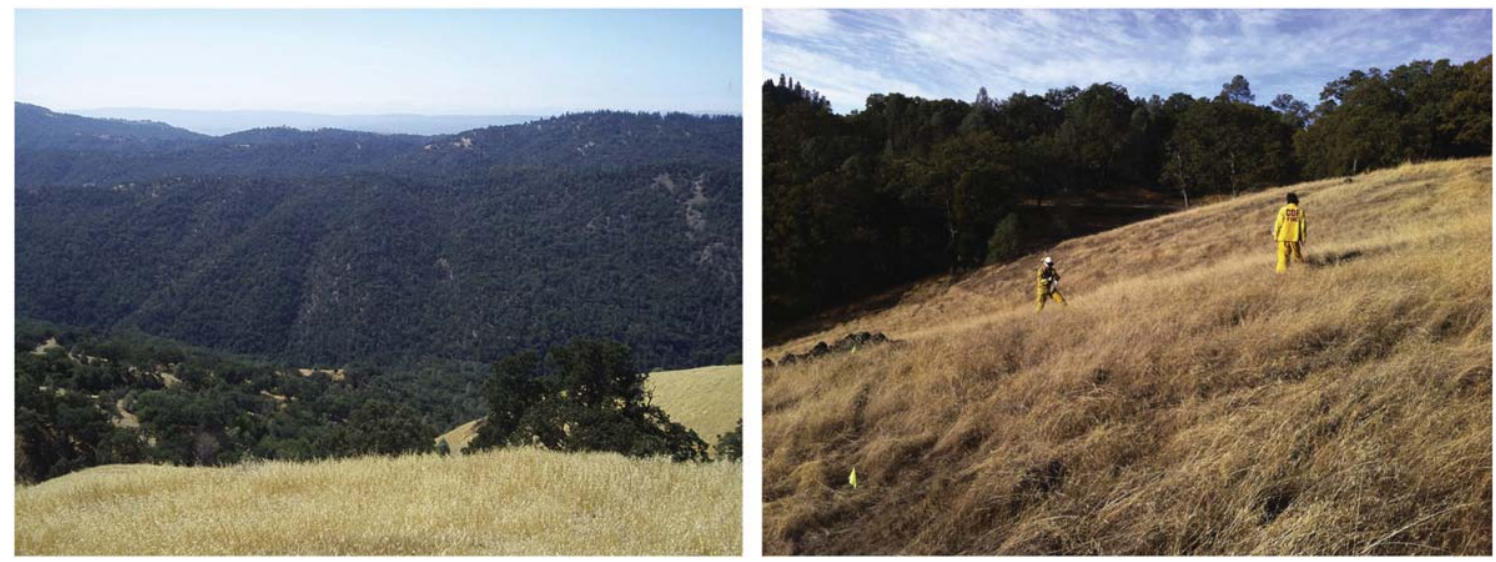

Fig. 1. Ground views of the prescribed fire site. Vegetation forms included grassland, oak woodland and ponderosa pine forests distributed over a rugged terrain.

(MWIR) sensor has a Calcium Fluoride $\left(\mathrm{CaF}_{2}\right)$ window with a bandpass of approximately $0.15-12.5 \mu \mathrm{m}$ and average window transmission of 0.6. The longwave infrared (LWIR) sensor has a Germanium window with a bandpass of approximately $6.5-20 \mu \mathrm{m}$ and average window transmission of 0.7 . Sensor output is in $\mathrm{mV}$, and was logged at $5 \mathrm{~s}$ intervals. The field of view is approximately $47^{\circ}$ for these singleaperture sensors. As described in Dozier (1981), retrievals from a dual-band radiometer rely on the fact that, for an assumed blackbody or graybody radiation source, the ratio between any two infrared bands is related to the kinetic temperature of the source. Recent experiments have validated the blackbody/graybody assumption for flames (e.g., Àgueda et al. (2010)) confirming that the atomic line emissions in exceedingly narrow bands from hot gases add little to total flame radiation (see Kremens et al. (2012)). The emissivity-area product is calculated by Dozier's (1981) method, the area roughly corresponding to the combustion zone to which the FRP estimate applies.

\subsection{Airborne fire remote sensing}

The airborne fire retrievals were derived from multi-spectral data acquired by the AMS sensor flown aboard a NASA-Dryden Flight Research Center (DFRC) Beachcraft King Air B200 aircraft (N801NA). The AMS is a line-scanner sensor and was operated using a 16-channel configuration, including four dual-gain channels in the shortwave (SWIR), MWIR and LWIR spectral regions providing enhanced dynamic range in support of active fire imaging. Table 1 lists all 12 unique AMS spectral bands, and their primary use in this study. The sensor had a total field of view of $85.9^{\circ}$ and an instantaneous field of view of $2.5 \mathrm{mrad}$, rendering $\sim 8 \mathrm{~m}$ resolution pixels when operating at a nominal

Table 1

List of AMS spectral channel configuration and primary uses in this study.

\begin{tabular}{lcl}
\hline Channels & Wavelength $(\mu \mathrm{m})$ & Primary use \\
\hline 1 & $0.424-0.452$ & Smoke visualization (qualitative) \\
2 & $0.452-0.517$ & Background visualization (qualitative) \\
3 & $0.518-0.589$ & Background visualization (qualitative) \\
4 & $0.568-0.635$ & Background visualization (qualitative) \\
5 & $0.596-0.677$ & $\begin{array}{l}\text { Normalized difference vegetation index } \\
\text { (NDVI) }\end{array}$ \\
& & Background visualization (qualitative) \\
6 & $0.639-0.751$ & Normalized difference vegetation index \\
7 & $0.699-0.869$ & (NDVI) \\
& & Differenced normalized burn ratio (dNBR) \\
8 & $0.798-1.034$ & Background visualization (qualitative) \\
$9 \& 13$ (dual-gain) & $1.578-1.772$ & Active fire visualization (qualitative) \\
$10 \& 14$ (dual-gain) & $2.076-2.345$ & Differenced normalized burn ratio (dNBR) \\
$11 \& 15$ (dual-gain) & $3.665-3.813$ & Fire detection, FRP, size, temperature \\
$12 \& 16$ (dual-gain) & $10.037-11.167$ & Fire detection, size, temperature \\
\hline
\end{tabular}

height above ground of $10,000 \mathrm{ft}$. This configuration provided a total of 716 samples for each scan line, covering a swath approximately $5.5 \mathrm{~km}$ wide. The sensor was calibrated pre- and post-flight in a NASA spectral laboratory using an integrating sphere for the visible and SWIR channels, with which calibration parameters were calculated for each flight using linear-interpolation, complemented by an onboard blackbody device providing calibration coefficients for the MWIR and LWIR channels.

A comprehensive image-processing algorithm was developed as part of this study to use with the AMS data, including an image classification product (fire mask) and the associated pixel-based FRP, fire size and temperature retrievals. The algorithm built on a contextual approach using primarily the MWIR $(3.7 \mu \mathrm{m})$ and LWIR $(11 \mu \mathrm{m})$ data to detect active fire pixels and separate them from the background, with customized tests optimized for the sensor's spatial and spectral resolution. Candidate fire pixels were defined as those exceeding $350 \mathrm{~K}$. Then, contextual tests were applied to classify pixels in the following two classes:

High intensity flaming:

$B T_{3.7}>\overline{B T_{3.7}}+3 \delta_{3.7}$ and $B T_{3.7}-B T_{11}>100$.

Lower intensity flaming/smoldering:

$B T_{3.7}>\overline{B T_{3.7}}+2 \delta_{3.7}$ and $B T_{11}>\overline{B T_{11}}+\delta_{11}$

where $B T_{i}$ is the brightness temperature on channel $i$, and $\overline{B T_{i}}$ and $\delta_{i}$ respectively are the mean and standard deviation of brightness temperatures calculated for background pixels using a sampling window starting at $100 \times 100$, increasing to $400 \times 400$ pixels until $20 \%$ of valid background pixels are found. Valid background pixels $\left(B T_{i b g}\right)$ must meet the following requirement:

$\overline{B T_{i_{-}}}-1.5 \delta_{i_{-} s}<B T_{i b g}<\overline{B T_{i_{-}}}+1.5 \delta_{i_{-}}$

where $\overline{B T_{i_{-} s}}$ and $\delta_{i_{-} s}$ are the scene's mean and standard deviation of brightness temperatures calculated for both MWIR and LWIR channels.

Algorithm tuning and verification were based on expert image analysis complemented by ground reports and instrument data. The quality assessment of the fire detection data derived from AMS found no outstanding pixel classification error. Pixels classified as fireaffected and fire-free matched all available ground data suggesting a high-fidelity product.

Fire characterization data were derived for all AMS pixels meeting tests (1) or (2) above. Pixel-based FRP estimates were produced using the radiance and brightness temperature retrieval methods (Kaufman, Justice, et al., 1998; Wooster et al., 2003), after consideration of the sensor's spectral response function in the MWIR channel. Results 
obtained from each retrieval method were comparable. Complementing the FRP retrievals, fire fractional area and temperature estimates were derived using a bi-spectral approach based on the MWIR and LWIR channel data (Dozier, 1981). The bi-spectral fire pixel analysis was implemented using a globally convergent Newton method to solve the system of two equations involved in the fire retrieval.

We used the Moderate Resolution Atmospheric Transmission (MODTRAN 4v3; Berk et al., 2003) code in order to estimate atmospheric attenuation affecting the quantitative fire characterization retrievals above. The required input data to operate the radiative transfer code were derived from the Oakland radiosonde station. We chose the atmospheric profile data from this location because of its proximity to HCSP (approximately $90 \mathrm{~km}$ northwest) and the frequency with which soundings are taken (approximately every $6 \mathrm{~h}$ ). In addition, a sensitivity analysis using various standard MODTRAN profiles revealed that the margin of difference in FRP was typically $<1 \%$. Thus, we concluded that using the radiosonde data from the Oakland site was both consistent and appropriate in order to best reflect the conditions during the prescribed fire.

AMS pixel geolocation information was available for each image file. Quality assessment was performed for all AMS images using independent sources and image-to-image analyses indicating highly accurate navigation data with subpixel geolocation errors.

A total of three separate airborne missions were flown over HCSP. The first mission on 13 October 2011 provided pre-fire mapping of the site's perimeter and adjacent areas. A second mission on 18 October 2011 targeted the prescribed fire at HCSP, with multiple overpasses flown in order to provide near-coincident acquisition with both Terra and Aqua MODIS, and GOES-11 (west) and -13 (east) imager data, as well as with AVHRR series aboard NOAA-15, -16, -18, and -19, and METOP-A satellites. Lastly, a third airborne mission was flown on 19 October 2011 with the objective of mapping the post-fire surface conditions at the HCSP site. The AMS overflights were flown at approximately $10,000-12,000 \mathrm{ft}$ above ground. The AMS data processing outputs were projected using the Universal Transverse Mercator (UTM) coordinate system with a pixel spatial resolution of $10 \mathrm{~m}$.

\subsection{Spaceborne fire remote sensing}

The HCSP site was imaged by a suite of complementary moderate and coarse spatial resolution spaceborne instruments providing complete coverage during the pre-, active-, and post-fire periods. Despite our efforts to coordinate the ground activities with the most favorable imaging conditions from all major satellite systems available, CAL FIRE firefighters had to guide their activities based on the onset of adequate prescribed fire weather conditions to ensure a safe controlled burn environment and minimize risks to the adjacent communities. Nonetheless, fire ignition time and duration did successfully coincide with several satellite observations of the HCSP site providing ample material for our analyses.

The two MODIS images coinciding with the overpass of the Terra and Aqua satellites were acquired at 18:25 $\mathrm{h}$ and $21: 40 \mathrm{~h}$ on the day of the fire (18 Oct 2011). The HCSP site was imaged at scan angles of $45^{\circ}$ and $39^{\circ}$ by MODIS onboard Terra and Aqua, respectively, corresponding to $3.6 \mathrm{~km}^{2}$ and $2.5 \mathrm{~km}^{2}$ equivalent ground pixel areas, respectively. Both images showed coincident fire detection produced by the Fire and Thermal Anomalies Collection 5 product (also known as MOD14 and MYD14 for MODIS Terra and Aqua, respectively) (Giglio et al., 2003), resulting in one Terra/MODIS fire pixel and four Aqua/MODIS fire pixels. The MODIS fire data used were downloaded from NASA's Level 1 and Atmospheric Archive and Distribution System (LAADS) and consisted of the geographic coordinates and top-of-atmosphere FRP retrievals for all fire pixels overlapping the HCSP site.

Complementing the MODIS data, a total of 23 GOES west images acquired between 19:30 h Oct 18th and 04:00 h Oct 19th showed coincident fire pixel detection for the site produced by the WF_ABBA product (Prins \& Menzel, 1992). The coincident GOES west fire pixels were imaged at a $42.5^{\circ}$ satellite zenith angle, resulting in a ground pixel area of $\sim 26 \mathrm{~km}^{2}$. Meanwhile, the GOES east imager was operating under a Rapid Scan Operation (RSO) mode during the prescribed fire, thereby enabling higher than usual observation frequency. A total of 37 images were acquired between 19:45 h (Oct 18th) and 02:02 h (Oct 19th) showing coincident fire detection pixels for the HCSP site. The coincident GOES east fire pixels were imaged at a $64.5^{\circ}$ satellite zenith angle, which is equivalent to a ground pixel area of $\sim 61 \mathrm{~km}^{2}$. The GOES fire data used in the analyses consisted of the geographic coordinates and top-of-atmosphere FRP retrievals for all fire pixels overlapping the HCSP site. We also used the standard WF_ABBA FRP data that incorporate additional procedures to correct for water vapor attenuation and to account for variable surface emissivity [Christopher Schmidt, personal communication]. The GOES imager WF_ABBA fire data were available through the Cooperative Institute for Meteorological Satellite Studies (CIMSS) at the University of Wisconsin-Madison.

The AVHRR NOAA-15, -18, and -19 acquired on 18 October 2011 showed saturated pixels overlapping the site, and therefore could not be used in the quantitative analyses that followed. The AVHRR NOAA16 and METOP-A showed non-saturated pixels coinciding with the cooling fire, approximately $6 \mathrm{~h}$ after the peak intensity was observed when no AMS reference data were available. Therefore we opted to exclude AVHRR data from the analyses.

\section{Results part I: Remote sensing fire retrievals}

The prescribed fire at HCSP was started on 18 October 2011 at approximately 1725 h UTC by CAL FIRE firefighters and California State Parks crews using conventional hand-carried drip torches as ignition sources, followed by aerial ignition using a manned helicopter spreading incendiary spheres over parts of the terrain. The initial fire ignition line extended for approximately $4 \mathrm{~km}$ running along a northwest-southeast corridor atop a ridgeline, allowing for the fire to spread downhill on both northeast and southwest slopes. The aerial ignition was concentrated on the northeast slope halfway between the ridgeline and the valley below, thereby allowing for intense uphill flame propagation.

AMS sensor operation was restricted by aircraft schedule to two periods of approximately $1 \mathrm{~h}$ each covering 17:30-18:30 h and 21:2022:20 h during which sequential data were collected. The first image of the fire produced by AMS was acquired at $\sim 17: 39 \mathrm{~h}$, when the active fire showed an estimated area of 0.3 ha. The initial fire spread was captured by multiple AMS overflights and is summarized in Fig. 2, with the aerial ignition lines clearly visible on the northeast slope in yellow and green color tones.

As the fire ignition lines expanded and coalesced, areas of continuous flaming activity were developed creating clusters of high fire intensity. The occurrence of saturated pixels in the AMS MWIR data followed the fire progress, gradually increasing from a low $0.6 \%$ saturation rate in the first image to a maximum of $2.3 \%$ in the image acquired at $\sim 22: 24 \mathrm{~h}$ that coincided with the spread of high-intensity uphill flaming fronts generated following the aerial fire ignition. While nominally small, these pixel saturation rates can have a disproportionate impact on retrieved FRP totals for each individual image. In order to mitigate the problem, histogram analysis of radiance and brightness temperature in the MWIR channel was used to estimate pixel values exceeding the saturation limit. Fig. 3 shows the AMS MWIR band brightness temperature histogram for the image acquired at $\sim 22: 24 \mathrm{~h}$, in which 20,379 pixels were classified as fire-affected including 461 that were saturated as evidenced by the spike in the frequency of data points at $619.5 \mathrm{~K}$ (i.e., the scene's saturation temperature). By fitting an exponential curve to the histogram, we projected the brightness temperature distribution exceeding the scene's saturation temperature until all 461 saturated pixels were accounted for. The maximum pixel brightness temperature obtained with this approach was equivalent to $\sim 725 \mathrm{~K}$. While residual differences between projected and actual 


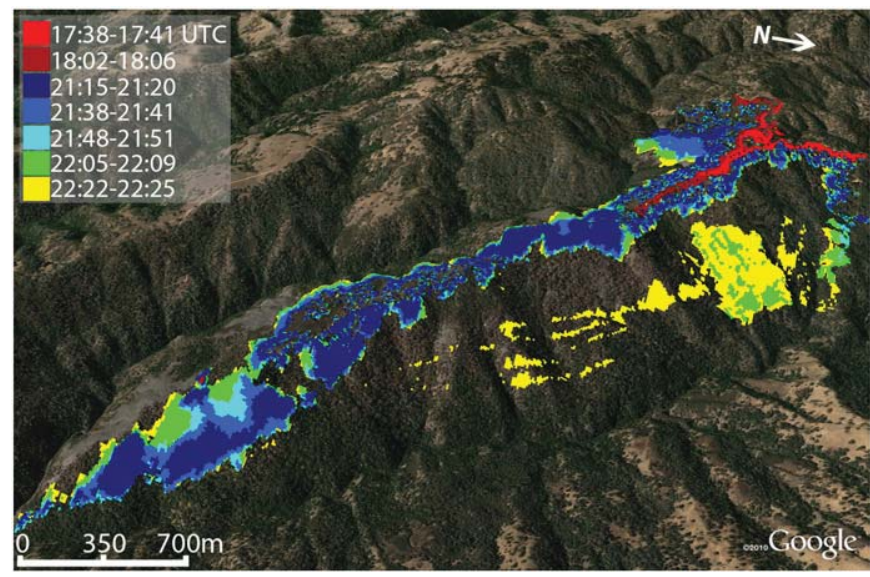

Fig. 2. Initial spread of prescribed fire at the Henry W. Coe State Park as seen by multiple images acquired by the AMS sensor aboard a NASA/Dryden King Air B200. Color vectors represent ground surface areas classified as fire in the AMS data, and are overlaid on a Google Earth terrain-corrected background showing a 31 October 2011 image.

brightness temperatures may still be present after implementation of the procedure above, we assume that those will be significantly less prominent and therefore should have only a negligible impact on the total FRP estimated.

Using the projected data derived for all 461 saturated pixels, revised FRP retrievals were calculated for the scene by randomly replacing saturated pixel values with projected ones assuming that fire pixel background conditions were comparable across the site. In order to assess the potential impact of random pixel assignment on the resulting FRP total, 10 different random combinations were tested. The total scene FRP retrieved increased by approximately $9 \%$ after replacing the saturated pixels values with the projected data. Alternating the assignment of projected pixel data using 10 random combinations resulted in $1 \%$ difference in the total FRP calculated for the scene, which increased between 8.6 and $9.6 \%$ compared to the uncorrected retrieval. This procedure was replicated using other AMS scenes showing different pixel saturation rates in order to generate estimates for the revised FRP totals. Our results suggested a fairly robust linear relationship $\left(R^{2}=0.89\right)$ between the pixel saturation rate and the percentage increase in FRP totals after correction, described as follows:

$P_{\text {FRP }}=5.39 P_{\text {sat }}-2.8$

where $P_{F R P}$ is the percentage FRP increase and $P_{\text {sat }}$ is the pixel saturation rate (\%). Consequently, pixel saturation rates lower than $0.5 \%$ resulted in negligible impact on the total FRP calculated based on a sample of AMS fire pixels analyzed.

In addition to pixel saturation errors, AMS fire size and temperature estimates derived using the bi-spectral (Dozier) approach were also in part affected by limitations intrinsic to that retrieval method (Giglio \& Kendall, 2001). In this case, the problem was caused by the mathematical processing of the pair of equations used in the bispectral method resulting in an invalid solution. Invalid solutions occurred predominantly along the edges of the fire pixel clusters detected, and were believed to be linked to potential incompatibilities in the MWIR and LWIR data derived for the target pixel and/or background, as well as due to any unresolved band-to-band misregistration (see Giglio and Kendall (2001) for a detailed discussion of potential limitations in the bi-spectral fire retrieval). On average, these invalid retrievals affected approximately $19 \%$ of the fire pixels processed. Fortunately, all pixels used in the analyses based on ground and airborne data were successfully processed generating valid fire size and temperature estimates. In order to derive first order fire area
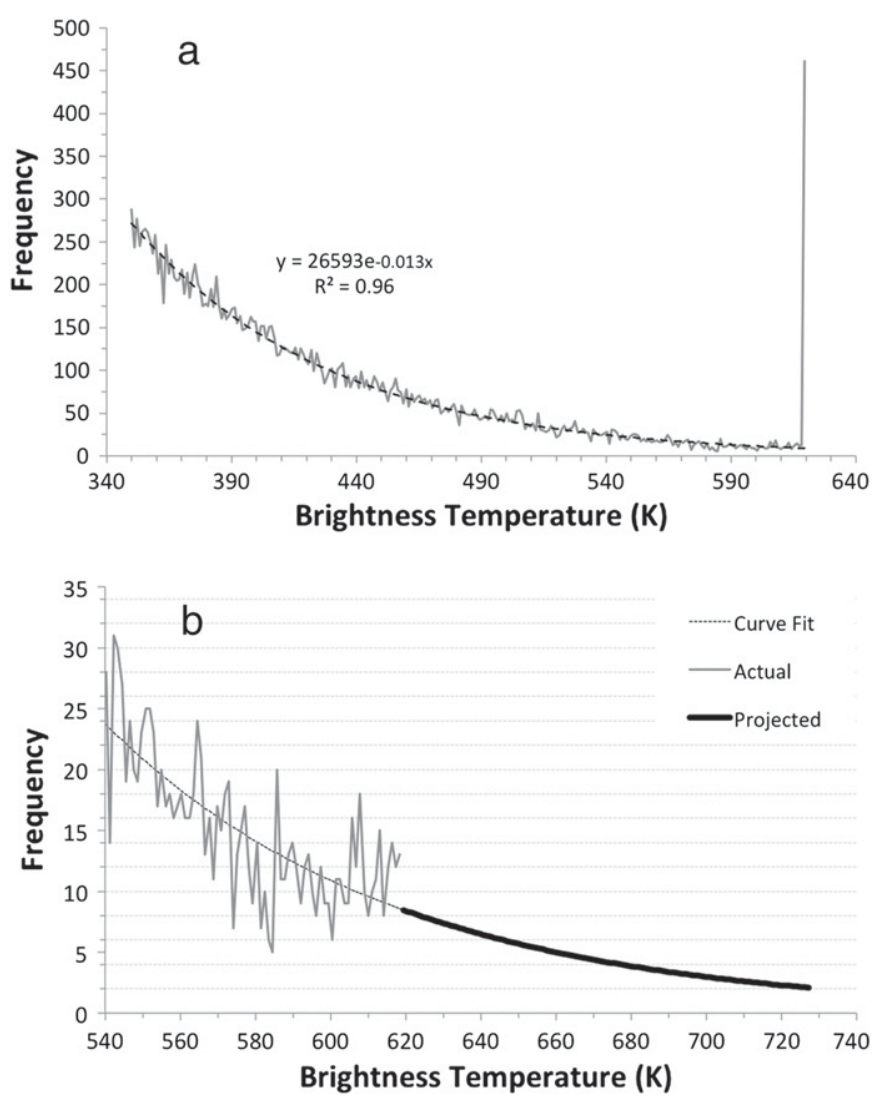

Fig. 3. AMS middle infrared fire pixel brightness temperature histogram for a single scene containing 20,379 fire pixels, including 461 saturated ones (a). An exponential curve was fitted to the data, and used to project pixel values beyond the saturation temperature of $619.5 \mathrm{~K}$ (b). Right panel highlights the high end data points on left panel, where all 461 saturated data points are replaced with the projected curve.

estimates to use in support of the spaceborne data analyses, AMS fire pixels containing invalid size estimates were replaced with the mean value calculated using the available valid retrievals.

\subsection{Coincident ground and airborne retrievals}

The ground plots were located at the western end of the burn perimeter, and were subjected to a free-moving fire front ignited approximately $50 \mathrm{~m}$ away by firefighters carrying a drip torch with flames spreading in a downhill direction. Flames reached the groundbased radiometers at unique times with first and last site separated by approximately $20 \mathrm{~min}$. Due to the terrain configuration and the fire line ignition process, which followed a winding road near the ridgeline, the AMS overflights could not be choreographed to precisely match the fire front progression and interaction with the ground-based radiometers. Nonetheless, a total of six AMS images were acquired during an interval of approximately 47 min coinciding with the fire line ignition and combustion of the fuel bed underneath and around all three ground radiometers (Fig. 4). A total of three AMS images were acquired within less than 3 min from the time when the fire front intercepted each ground radiometer (Fig. 4). The site selection provided a rather homogeneous fuel bed resulting in fairly steady fire spread and flame conditions, which was confirmed by ground observations. Consequently, we assumed that the AMS sampling of the ground plots was representative of the fire conditions measured by the ground radiometers and fuel data collected.

The ground-based radiometer data provided $0.2 \mathrm{~Hz}$ sampling frequency of radiant heat flux. Peak radiant heat flux across the three sites varied between 10.9 and $27.1 \mathrm{~kW} \cdot \mathrm{m}^{-2}$, with flame residence times of less than 2 min (Fig. 4). These were consistent with previous 

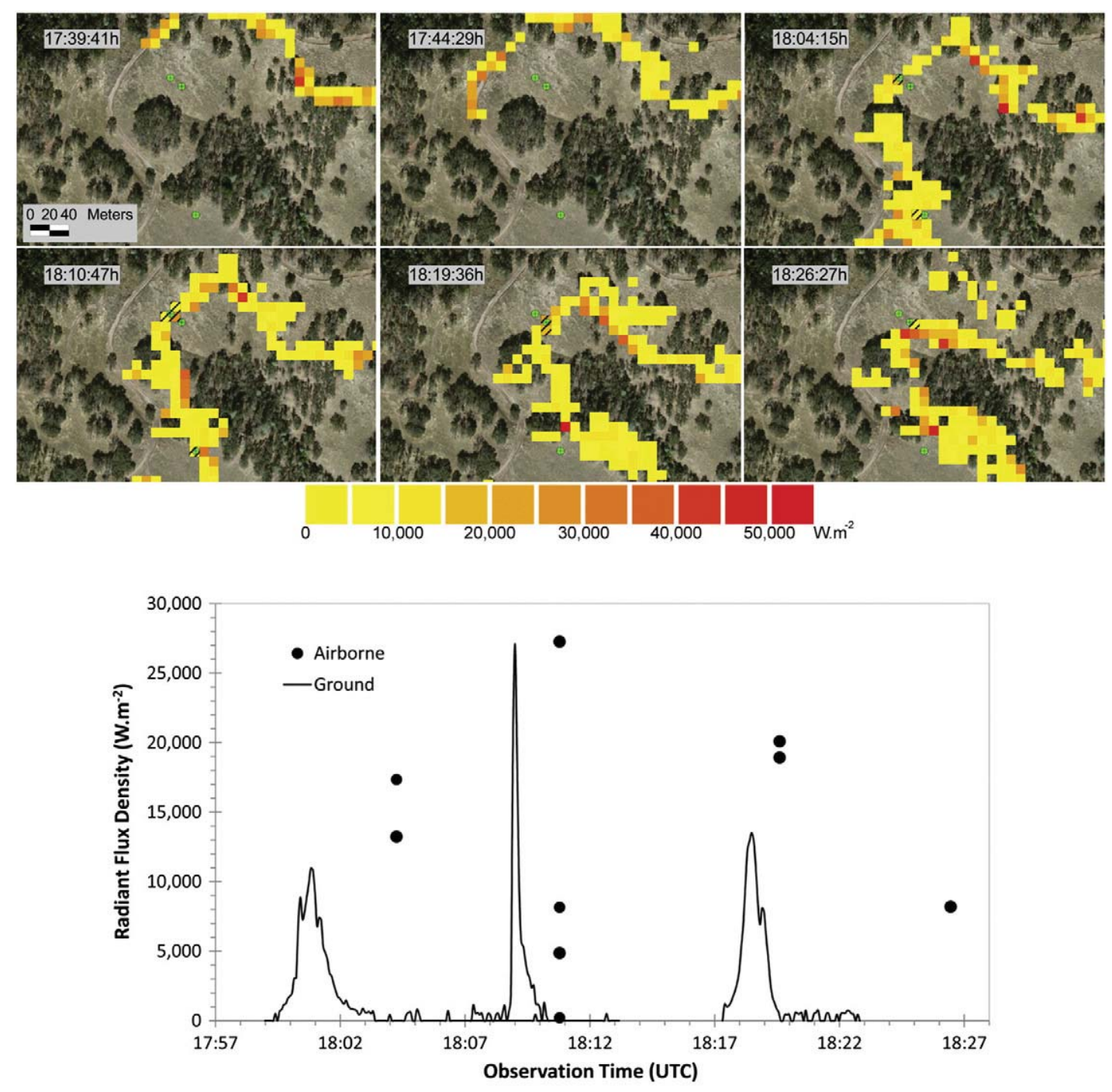

Fig. 4. Fire line ignition and initial spread across area containing ground radiometers (green markers) as mapped by AMS (top panel). Radiant flux density estimates derived from AMS for all classified active fire pixels are depicted in the colored table provided. Near-coincident radiant flux retrievals derived from AMS and ground radiometers are also plotted (bottom panel). AMS pixels used for comparison with ground radiometers are indicated by stripping in the top panel.

estimates obtained in light fuels (Kremens et al., 2012). Derivation of radiant heat flux using AMS data was accomplished via calculation of FRP using the radiance method of Wooster et al. (2003), divided by the sub-pixel fire area estimates derived from the application of the bi-spectral method of Dozier (1981) to individual pixels. Because of the relatively lower fire intensity in the grassland area containing the ground plots, no AMS pixel saturation was found. Similarly, fire size and temperature estimates were successfully retrieved for all pixels overlapping the ground radiometers. A total of nine AMS pixels found within approximately $5 \mathrm{~m}$ radius from each ground radiometer were selected as being representative of those sites. The peak radiant heat flux estimated from AMS measurements was equivalent to $27.3 \mathrm{~kW} \cdot \mathrm{m}^{-2}$, and within $0.6 \%$ of the peak value measured by the ground radiometers (Fig. 4). Average radiant heat flux estimated using all nine AMS pixels selected was equivalent to $13.2 \mathrm{~kW} \cdot \mathrm{m}^{-2}$, which may confirm the prevailing flaming component that dominated the combustion and consequently the fire signal in the MWIR band on AMS relative to the peak fire flux measured by the ground radiometers. The average pixel-based fire area derived from AMS pixels over the ground plots was estimated at approximately $10 \mathrm{~m}^{2}$ (a fractional fire area of 0.1 in a $100 \mathrm{~m}^{2}$ pixel) which would be equivalent to a $1 \mathrm{~m}$-deep flame front spreading linearly across the $10 \mathrm{~m}$ pixel. This flame front estimate was considered consistent with the conditions observed in situ across the area where the ground plots were positioned. Collectively, ground-based and airborne retrievals showed good overall agreement. After consideration of the differences in sampling time and footprint of the two data sets, we assumed the AMS fire retrievals to be a high quality product. We therefore applied AMS absolute fire retrievals as our ground truth reference data in the subsequent satellite fire retrieval and emissions analyses recognizing, however, that a larger sample would be required to establish the appropriate AMS accuracy estimates.

\subsection{Coincident airborne and spaceborne retrievals}

\subsubsection{MODIS fire detections}

The first confirmed spaceborne active fire detection of the fire at HCSP on 18 October 2011 was provided by the 18:26:15 h MODIS overpass aboard the Terra satellite. The MOD14 fire data showed one fire pixel matching the HCSP site (Fig. 5). A near-coincident AMS image was acquired only $13 \mathrm{~s}$ after the Terra satellite overpass at 18:26:28 h. The active fire area estimate derived from AMS data was equivalent to 0.71 ha, representing approximately $0.2 \%$ of the coincident Terra/ MODIS pixel footprint. Terra/MODIS produced a top of atmosphere FRP of $42.7 \mathrm{MW}$, and surface FRP of 53.9 MW after atmospheric correction. 

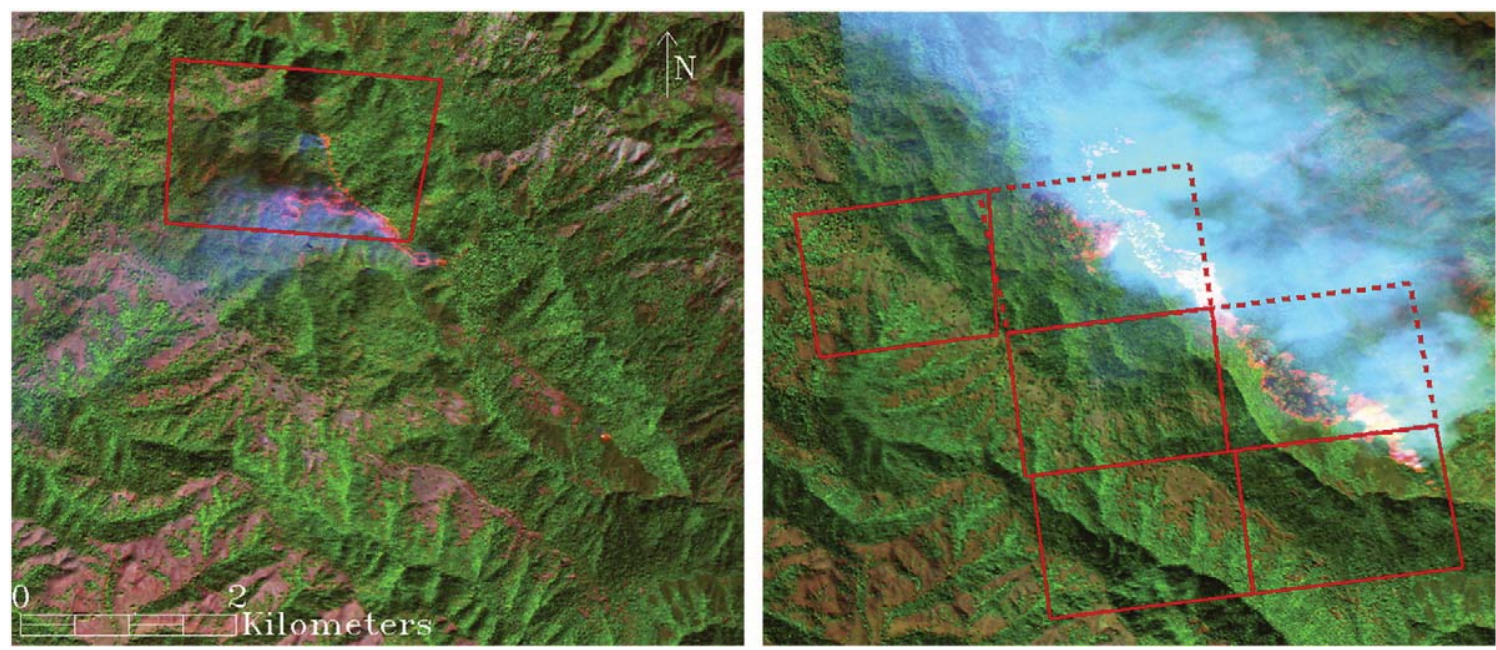

Fig. 5. Terra/MODIS (left panel) and Aqua/MODIS (right panel) fire detection pixel footprints overlapping with the prescribed fire at HCSP. Background shows near-coincident AMS data in a natural color RGB 10-8-4 band combination highlighting green vegetation, fires (red shades), and smoke (light gray). Dashed Aqua/MODIS pixel footprint indicates fire detection omission caused by bright surface filter using MODIS channel 2, which was misled by the presence of thick smoke.

The AMS fire retrievals produced an at-sensor FRP of $65.9 \mathrm{MW}$, and an estimated surface FRP of $72.7 \mathrm{MW}$. The AMS surface FRP retrieval included a $1.6 \%$ correction for pixel saturation and $8.8 \%$ atmospheric correction. Use of surface-equivalent and corrected fire retrievals allowed for a reduction in the difference between Terra/MODIS and AMS FRP from $35 \%$ to $26 \%$. Other factors such as background pixel characterization and MODIS pixel point spread function (PSF) are known to influence FRP retrievals (Schroeder, Csiszar, Giglio, \& Schmidt, 2010). The paired MODIS-AMS background pixel brightness temperatures showed less than $\sim 1 \mathrm{~K}$ difference in this case, therefore we ruled out any significant contribution from that term. Given the large Terra/MODIS pixel footprint coinciding with HCSP, we inferred that PSF was the primary factor driving the residual difference with the paired AMS FRP estimate. A PSF-corrected MODIS FRP retrieval was not attempted as proper Terra/MODIS-AMS image co-registration could not be achieved due to the limited geographic extent of those overlapping data sets and the complexity of the terrain.

The MYD14 product derived from the Aqua/MODIS image acquired at 21:42:49 $\mathrm{h}$ produced four fire pixels coinciding with the HCSP site with a total top of atmosphere FRP of $226.5 \mathrm{MW}$, and surface FRP of 276.4 MW after atmospheric correction (Fig. 5). That MODIS observation was matched by a near-coincident AMS image acquisition at 21:43:15 h showing an at-sensor FRP of $458.8 \mathrm{MW}$, and a surface FRP estimate of $522.8 \mathrm{MW}$, including a $4.75 \%$ correction for pixel saturation and $8.8 \%$ atmospheric correction, and a fire area of 4.03 ha. The larger relative difference separating AMS and Aqua/MODIS FRP retrievals can be explained by an omission error impacting the latter. Close inspection of the Aqua/MODIS L1B radiance data revealed two additional pixels adjacent to the HCSP with brightness temperatures of 328.7 and $337.0 \mathrm{~K}$, both exceeding the $325 \mathrm{~K}$ mean value found for the fire pixel cluster detected by the MYD14 product (Fig. 5). The omission error was attributed to the presence of thick smoke associated with the fire, which triggered a filter in the MODIS detection algorithm that uses data on the visible channel $2(0.86 \mu \mathrm{m})$ to screen for highly reflective surfaces (e.g., clouds and bare soil; see Giglio et al. (2003)) Inclusion of those two extra pixels resulted in a top of atmosphere FRP total of $386.7 \mathrm{MW}$, and surface FRP of $470.1 \mathrm{MW}$ after atmospheric correction, thereby significantly reducing the difference from the nearcoincident AMS retrieval. In addition to the omission error above, unusually high geolocation error $(\sim 1 \mathrm{~km})$ can be seen in the section of the Aqua/MODIS image overlapping HCSP, which we believed to be in part due to the area's rugged terrain. Similar to the Terra/MODIS data, use of FRP retrievals corrected for atmospheric attenuation and AMS pixel saturation reduced the difference between Aqua/MODIS and AMS FRP estimates, changing from 16\% (uncorrected) to 10\% (surface/ corrected). Further analyses of the Aqua/MODIS data indicated a fire pixel background brightness temperature approximately $2 \mathrm{~K}$ warmer than estimated using AMS data. Replacing the original background estimate with the revised one led to further improvement of the Aqua/MODIS FRP estimate, leaving it within approximately 5\% of the AMS reference surface estimate. We concluded that, in this case, a larger fire cluster might have helped minimize the potential detrimental effects of the PSF on MODIS total FRP retrieval.

\subsubsection{GOES imager fire detections}

Several WF_ABBA active fire pixels were derived from GOES imager east and west data for the HCSP prescribed fire. The first detection by both satellites occurred near simultaneously at 19:30 h and 19:45 h for GOES west and east, respectively. As mentioned above, GOES east was operating under a Rapid Scan mode acquiring data at a higher than usual frequency. Fire pixels were observed for approximately six consecutive hours by WF_ABBA/east, and for 8.5 consecutive hours by WF_ABBA/west (Fig. 6). The extended fire detection achieved using GOES west data can be explained by the difference in pixel spatial resolution between west and east imagers, which at the HCSP location, showed pixel footprints of 26 and $61 \mathrm{~km}^{2}$, respectively. The coarser spatial resolution of GOES east resulted in reduced response to the prescribed fire, which in that case occupied a smaller fraction of the pixel compared to GOES west data. Up to two adjacent fire pixels were detected by the GOES east and west data sets during most observation hours. However, the WF_ABBA product reported only one fire pixel for each data set after accounting for the imager's spatial oversampling. Also, several observation hours showed no FRP retrieval in the output WF_ABBA products for GOES east and west, as pixels were classified as "cloudy". Similar to the Aqua/MODIS omission error described above, we attributed this classification to the thick smoke plume that developed adjacent to the fire perimeter extending several tens of kilometers in the north-northeast direction. Nonetheless, we were able to generate supplemental FRP retrievals for all pixels classified as cloudy using the available WF_ABBA metadata (Fig. 6).

Large differences in GOES fire retrievals were found comparing the standard WF_ABBA FRP output, which is corrected primarily for variations in ambient water vapor and surface emissivity, with the top-of-atmosphere-equivalent (uncorrected) FRP data. On average, the standard WF_ABBA correction applied to GOES east data resulted in a $47 \%$ increase in derived FRP compared to the top-of-atmosphere 

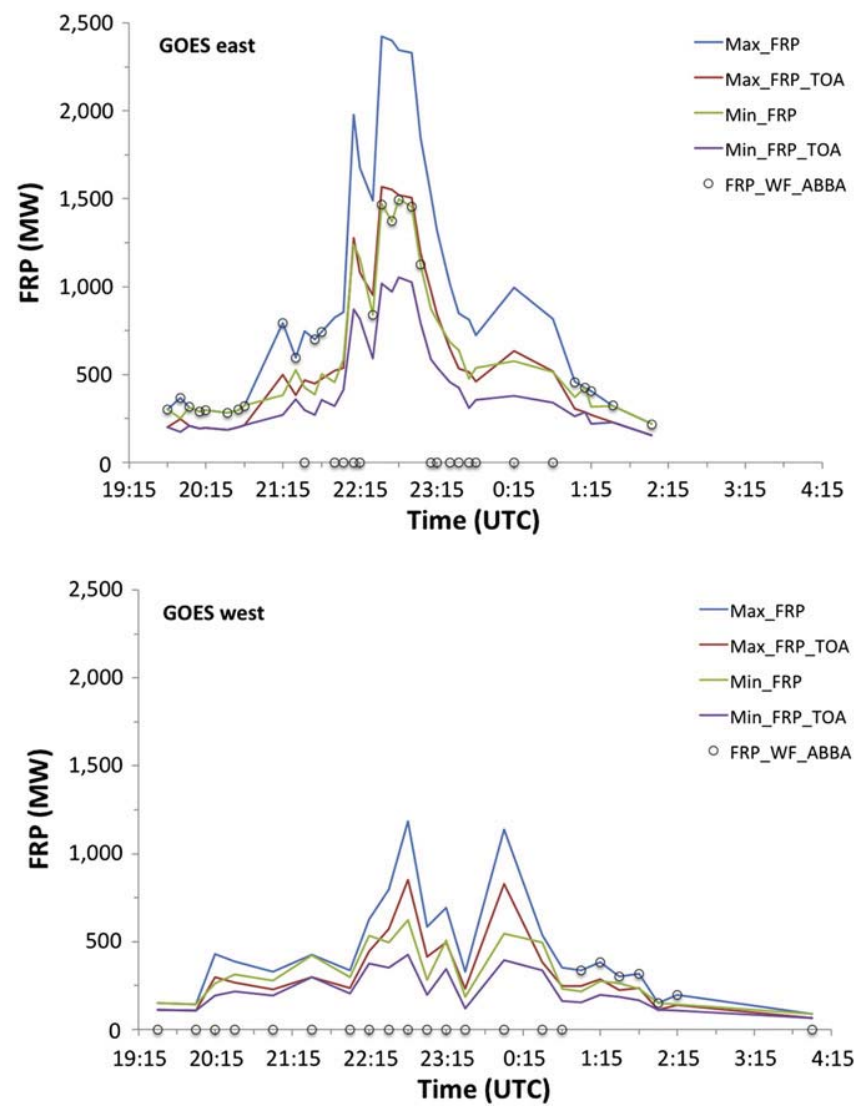

Fig. 6. GOES imager east (13) and west (11) FRP retrievals coincident with prescribed fire at HCSP. Up to two adjacent fire pixels were processed during each observation time (Max_FRP and Min_FRP), and only one pixel reported by the WF_ABBA product after accounting for the imager's pixel spatial oversampling (circles). Markers appearing along the horizontal axis indicate WF_ABBA pixels classified as "cloudy" for which no FRP data was made available with the operational product. Top of atmosphere FRP retrievals are also displayed for each fire pixel detection (Max_FRP_TOA and Min_FRP_TOA).

equivalent, whereas GOES west data showed a $41 \%$ increase. These fairly significant correction factors reflect the highly oblique viewing angles at which both imagers observed the fire. An alternative calculation of the atmospheric attenuation (assuming a surface emissivity of 0.99) using MODTRAN produced somewhat comparable, albeit lower, correction factors. For example, WF_ABBA corrections of 41.5 and $56.1 \%$ were derived for the two GOES east pixels detected at 21:40 UTC, compared to $37.8 \%$ atmospheric correction using MODTRAN and the nearby radiosonde data.

The largest differences in FRP retrievals originated, however, from the oversampled fire pixels produced by both GOES east and west imagers during most observation hours with WF_ABBA fire detection (Fig. 6). As mentioned above, oversampling across the east-west scanning direction results in approximately 50\% overlap between adjacent GOES imager pixels. Consequently, detected active fires often produce a minimum of two WF_ABBA pixels describing the same event thereby introducing some redundancy in the fire retrieval data. In order to compensate for this unique sampling feature, the WF_ABBA algorithm selects the highest FRP from any two adjacent pixels with valid calculated values. In cases when the pixel with the highest FRP is flagged as "cloudy" and the adjacent pixel with the lower FRP is not cloudy, the lower FRP value is used. In the case of the HCSP fire, differences of up to $110 \%$ separated the oversampled WF_ABBA FRP retrievals. More importantly, the highest of each two WF_ABBA FRP retrievals produced was systematically above the available near-coincident reference AMS FRP data. Analyses of the WF_ABBA background fire pixel data suggested a small cold bias ( $\leq 2 \mathrm{~K}$ ), which could have artificially raised the calculated FRP by as much as $15-20 \%$. Removal of such potential background bias would leave a residual 10-15\% GOES FRP (atmospherically-corrected, emissivity $=0.99$ ) overestimation compared to the reference AMS data. While no clear evidence of additional biases could be distinguished, we speculate that potential smoke interference could have raised the solar reflection on the GOES imager MWIR channel over the target pixel. This could potentially inflate the associated brightness temperatures resulting in overestimated FRP retrievals.

\section{Results part II: FRE-based biomass consumption and emissions}

The common approach to estimate emissions from wildland fire is based on the use of an a priori emission factor for the atmospheric species (gas or aerosol) of interest, which is multiplied by an estimate of the fuel consumed:

$E_{x}=E F_{x} \times M$

where $E_{x}$ is the emission load of species $x(\mathrm{~g}) ; E F_{x}$ is the emission factor for species $x$ for the specific vegetation type or biome $\left(\mathrm{g} \mathrm{kg}^{-1}\right)$; and $M$ is the biomass burned $(\mathrm{kg})$. The biomass burned is calculated using:

$M=A \times B \times \beta$

where $A$ is the burned area $\left(\mathrm{km}^{2}\right)$; $B$ is the biomass or fuel load $\left(\mathrm{g} \mathrm{km}^{-2}\right)$; and $\beta$ is the combustion factor (fraction of available fuel burned). Given the advantage of synoptic, frequent observations from spaceborne sensors, the ab ove equations are often employed using remotely sensed data. However, the combustion factor cannot be measured from space and the uncertainty in space-based measurements of burned area and fuel loads is high (e.g., Kasischke and Penner (2004), Korontzi, Roy, Justice, and Ward (2004)). As discussed in the Introduction section, previous research has demonstrated the relationship between radiative flux and energy to instantaneous and total fuel consumption. Ichoku and Kaufman (2005) investigated the relationship between regional estimates of FRP and aerosol emissions from MODIS in order to establish a connection between fire energy and emissions. They also defined the term FRE-based emission coefficient to describe the relationship while avoiding confusion with the traditional emission factor term. Freeborn et al. (2008) followed up on Ichoku and Kaufman's work by conducting laboratory experiments of indoor fires and clearly demonstrated a relationship between FRE, fuel consumption, and gas $\left(\mathrm{CO}, \mathrm{CO}_{2}, \mathrm{NO}\right.$, $\left.\mathrm{NO}_{2}\right)$ and aerosol $\left(\mathrm{PM}_{2.5}\right)$ emissions. The rationale for using FRP/FRE is to reduce the uncertainty in estimating biomass burned and emissions while utilizing the synoptic capabilities offered from remote sensing platforms.

Our first step to estimate emissions from the HCSP prescribed fire was to establish the FRE-fuel consumption relationship at the microscale using the estimates of pre- and post-fire fuel loading and the FRE values from the three ground radiometers. The average total energy estimated from all radiometers was $0.738 \mathrm{MW} \mathrm{m}^{-2}$ while the total fuel consumed was $0.193 \mathrm{~kg} \mathrm{~m}^{-2}$, thus establishing an FRE-based fuel consumption factor of $0.261 \mathrm{~kg} \mathrm{MJ}^{-1}$.

Extrapolating fuel consumption for the entire fire required estimating the total energy emitted over the lifespan of the fire. To this end, the suite of imagers observing the fire (described in Section 2.4) were used to calculate a series of instantaneous energy release rates, or FRP, which were collectively used to calculate the integrated energy from all observations available. When an observation was made by more than one sensor at nearly the same time, the average FRP value was used (Fig. 7). In addition, FRP is normalized by the area of the observation (pixel size in this case), and thus reduces uncertainty in the estimates of FRP from the various sensors. The FRE from the HCSP prescribed fire was estimated to be $14.5 \mathrm{e}+06 \mathrm{MJ}$ using a simple stepwise summation technique. If we were to use the minimum or maximum FRP value when more than one sensor observed the fire at the same time, our range of FRE would vary by less than $8 \%$. 


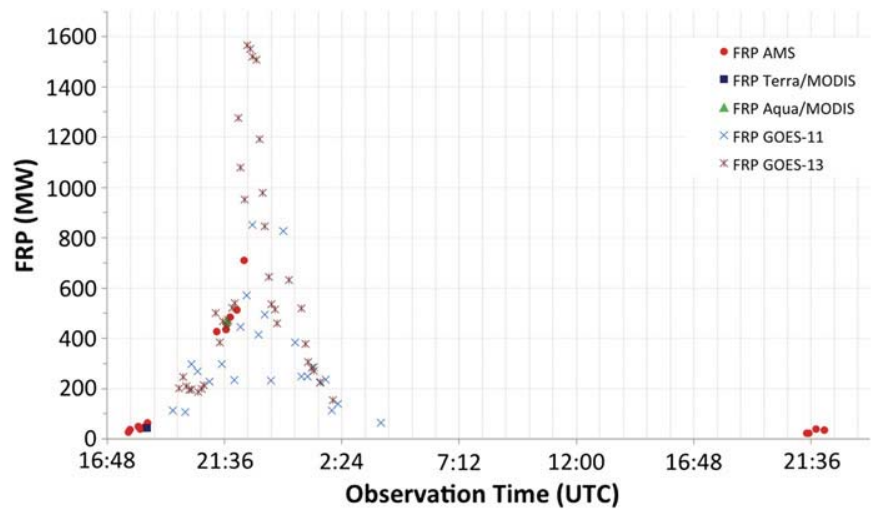

Fig. 7. Summary of all airborne and spaceborne FRP retrievals for the prescribed fire at HCSP.

By applying the FRE-derived fuel consumption factor of $0.261 \mathrm{~kg} \mathrm{MJ}^{-1}$ established from the fuel plots to the FRE estimate for the entire fire, we arrived at a total fuel consumption of $3.8 \mathrm{e}+06 \mathrm{~kg}$. It is likely that this value is at the lower end of the range of real fuel consumption as the fuel plots were dominated by fine fuels, mainly grass, and did not include some of the heavier fuel loads associated with woody vegetation scattered throughout the burn unit.

To estimate aerosol emissions, we used two similar, but different approaches to establishing FRE-based emission coefficients; the first FRE-based emission coefficient was produced by Vermote et al. (2009) for organic and black carbon aerosol (OCBC) emissions, hereafter referred to $E C_{O С B C}$; the second, a more direct method of estimating smoke aerosol emissions developed by Ichoku and Kaufman (2005), uses the coefficients of emission for total particulate matter (TPM), hereafter referred to, $C_{e}$. The governing relationship for both approaches is given by:

$M_{s a}=E C_{O C B C} \times$ FRE or $M_{s a}=C_{e} \times$ FRE

where $M_{s a}$ is the mass of smoke aerosol emission.

In the former case, we chose the $E C_{O C B C}$ for savanna land cover $\left(0.0025 \mathrm{~kg} \mathrm{MJ}^{-1}\right)$ produced by Vermote et al. (2009) because this most closely resembles the ecosystem type burned at the HCSP experiment. The OCBC emission was thus estimated to be $3.6 \mathrm{e}+04 \mathrm{~kg}$. We estimate the $\mathrm{PM}_{2.5}$ emitted to be $5.0 \mathrm{e}+04 \mathrm{~kg}$ by assuming the fraction of OCBC in $\mathrm{PM}_{2.5}$ to be 0.72 for savanna vegetation (see Andreae \& Merlet, 2001). We point out that the $E C_{O C B C}$ developed by Vermote et al. (2009) was based on larger temporal/spatial sampling windows, thus not site specific, and was generated from FRE estimates made only from AquaMODIS.

For the second FRE-based emission coefficient approach (i.e., $C_{e}$ ), the key is in generating an accurate $C_{e}$ for this particular fire. Although a regional $C_{e}$ of $0.00164 \mathrm{~kg} \mathrm{MJ}^{-1}$ has been calculated in the $1 \times 1^{\circ} C_{e}$ product released by the Fire Energetics and Emission Research (FEER) team (Ichoku \& Ellison, 2013), the quality flag of zero for that location implies that there is great uncertainty in using that particular $C_{e}$ value for analysis, especially for a localized analysis on one particular fire event such as this HCSP experiment. Therefore, the same algorithm as presented in that paper to generate $C_{e}$ is utilized to derive a customized and more realistic value of $C_{e}$.

In the Ichoku and Ellison (2013) algorithm, the rate of smoke aerosol emission $\left(R_{s a}\right)$ is calculated for each MODIS aerosol pixel $(10 \mathrm{~km}$ resolution at nadir) containing MODIS fire pixels $(1 \mathrm{~km}$ resolution at nadir) by using surrounding MODIS aerosol optical depth (AOD) values (Levy, Remer, Tanré, Mattoo, \& Kaufman, 2009; Remer et al., 2005), relative locations of the fires from the MODIS fire product, and wind speeds and directions from the Modern Era Retrospective-Analysis for Research and Applications (MERRA) reanalysis data set (Acker \&
Leptoukh, 2007; Rienecker, Suarez, Todling, et al., 2008). In order to generate a specific $R_{s a}$ for this HCSP fire, each of these parameters must be known. These parameters are readily available, with the exception that the proper plume injection height must be identified in order to use the most appropriate wind magnitudes. It is also crucial that the wind direction be aligned with the actual plume in order to generate a useful $R_{s a}$ value.

Fig. 8 shows MODIS 250-m resolution visible imagery acquired at the Terra and Aqua overpasses on 18 Oct 2011, with north oriented upwards. Unfortunately, the case of Terra could not be used, as none of the wind directions at the 925,850 or 700 mbar pressure levels corresponded with the observed wind direction of $\approx 240^{\circ}$ azimuth, and the AOD values were associated with larger uncertainties, as the corresponding cloud mask indicated the presence of clouds where visual analysis showed smoke. Furthermore, the fire was still very small at the time of Terra overpass, which is earlier than that of Aqua. Therefore, we resorted to using only the Aqua case, which provided a much clearer solution. From Fig. 8b it appears that the wind direction begins at $\approx 315^{\circ}$ azimuth and turns to $\approx 0^{\circ}$ when lofted to a higher altitude. Fortunately, the MERRA data set reports that at 850 mbar $(\approx 1.5 \mathrm{~km}$ MSL), the wind direction is at $304^{\circ}$ azimuth and at $700 \mathrm{mbar}(\approx 3 \mathrm{~km}$ MSL) it turns to $355^{\circ}$, thus the 850 mbar data was used as recommended in the original methodology (Ichoku \& Kaufman, 2005). The AOD values from the standard MODIS Collection 5 algorithm were excessively low due to the erroneous removal of the thickest part of the plume by the cloud masking procedure. At our request, the MODIS aerosol algorithm team conducted a custom retrieval for this specific plume such that no signal was eliminated in the cloud-masking step or other processing steps to enable a realistic retrieval of $R_{s a}$. After a final scaling was applied to compensate for the approximate $25 \%$ overlap between aerosol pixels as seen in Fig. 8c, an $R_{s a}$ value of $2.37 \mathrm{~kg} \mathrm{~s}^{-1}$ was obtained. Combining this value of $R_{s a}$ with the previously obtained omission-corrected topof-atmosphere FRP of $386.7 \mathrm{MW}$, a $C_{e}$ of $0.00612 \mathrm{~kg} \mathrm{MJ}^{-1}$ was obtained. It is pertinent to note that this $C_{e}$ value is subject to significant uncertainty since it is based on a single pair of AOD and FRP observations from Aqua-MODIS, as the typical method is to derive $C_{e}$ by zerointercept linear regression fitting to a statistically representative set of MODIS observations from both Terra and Aqua (Ichoku \& Ellison, 2013; Ichoku \& Kaufman, 2005)

By combining this $C_{e}$ value of $0.00612 \mathrm{~kg} \mathrm{MJ}^{-1}$ with the previously derived FRE value of $14.5 \mathrm{e}+06 \mathrm{MJ}$ for the entire lifetime of the fire, Eq. (7) yields an emission of total particulate matter (TPM) of $8.9 \mathrm{e}+04 \mathrm{~kg}$. Using corresponding "savanna and grassland" emission factors from Andreae and Merlet (2001) to generate emission ratios between different species and TPM, the following emissions estimates were obtained for the HCSP fire: $5.8 \mathrm{e}+04 \mathrm{~kg}\left(\mathrm{PM}_{2.5}\right), 3.9 \mathrm{e}+04 \mathrm{~kg}$ (TC), 3.6e $+04 \mathrm{~kg}(\mathrm{OC}), 5.1 \mathrm{e}+03 \mathrm{~kg}(\mathrm{BC}), 4.1 \mathrm{e}+04 \mathrm{~kg}(\mathrm{OCBC})$ and $17.2 \mathrm{e}+06 \mathrm{~kg}\left(\mathrm{CO}_{2}\right)$. Carbon emission $(4.7 \mathrm{e}+06 \mathrm{~kg})$ was estimated based on the ratio of $\mathrm{C}$ in $\mathrm{CO}_{2}$ (3.67). These estimates are higher than those from the previous method for OCBC and $\mathrm{PM}_{2.5}$ by about $15 \%$, whereas the estimate in this case for $\mathrm{C}$ and $\mathrm{CO}_{2}$ is a factor of 2.5 times higher than the simple estimate using the fraction of $C$ (assumed to be $50 \%$ here) in the biomass consumed.

As an additional comparison, we present in Table 2 emissions using the approaches presented earlier (Ichoku \& Ellison, 2013; Ichoku \& Kaufman, 2005; Vermote et al., 2009) and those from a "bottom up" approach. The bottom up emission estimates in column 2 were calculated as the product of biomass combusted and species-specific emission factors (see Eq. 5), as presented in Andreae and Merlet (2001), where biomass combusted $(\mathrm{kg})$ is the product of FRE and the combustion factor from the field plots (i.e., $0.261 \mathrm{~kg} \mathrm{MJ}^{-1}$ ). The third column in Table 2 reports the emissions for various species using the product of FRE and the emission coefficient reported earlier for OCBC $\left(E C_{O C B C} ; 0.0025 \mathrm{~kg} \mathrm{MJ}^{-1}\right.$ ) and then taking into account the ratio of the other species to OCBC (i.e. $E_{x}=\mathrm{FRE} * E C_{O C B C} / \mathrm{ER}$, where $\mathrm{ER}$ is the emission ratio of species $x$ and $O C B C$ ). Finally, the fourth column reports 

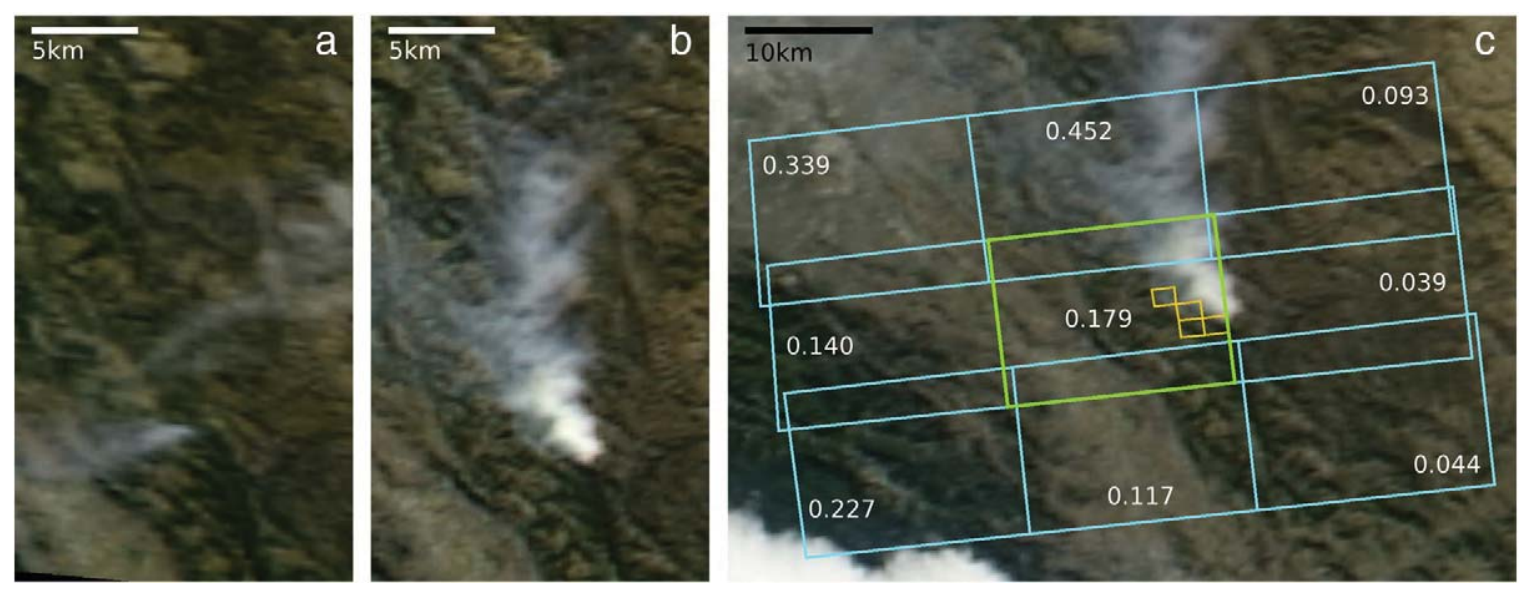

Fig. 8. MODIS view of the HCSP fire from: (a) Terra/MODIS (left panel) and (b) Aqua/MODIS (right panel) 250 m resolution MODIS RGB composites show snapshots of the HCSP fire and surrounding area at 18:26 and 21:43, respectively. (c) Aqua/MODIS showing the footprints of the fire pixels (yellow), and the aerosol pixels (blue and green) which are labeled with their respective AOD values.

the results using the methods described by Ichoku and Kaufman (2005) and Ichoku and Ellison (2013) to derive TPM emission and the corresponding ratio of the other species to TPM. The difference in emission estimates between the two FRE-based emission coefficient approaches presented in this paper (columns 3 and 4 ) is $15 \%$, as mentioned earlier. Comparison with the "bottom up" estimates in column 2 shows that the FRE-emission coefficient-based estimates in columns 3 and 4 are nearly a factor of two greater. It's worth noting that the emission values reported here are based on a simple stepwise integration estimate of FRE, whereas a more robust estimation of FRE using piecewise exponential curve fitting techniques reports a $15 \%$ increase in FRE. Therefore, the emissions estimations for all columns reported in Table 2 may be underestimated by that amount.

\section{Conclusions}

In this study we implemented a multi-level sampling of a 450 ha prescribed fire at the Henry W. Coe State Park in California. Pre- and post-fire in situ fuel load and consumption estimates were collected at several plots consisting of slender oat and blue wild rye. Reference fire energetics samples were derived during the active phase of the fire using dual-band ground radiometers and the AMS multi-spectral airborne sensor. The latter served as the primary bridge between ground and spaceborne fire retrievals.

Overall, agreement between ground and airborne fire data was high $(<1 \%$ absolute error for peak radiant heat flux), providing quality airborne reference data to subsequently assess satellite fire retrievals.

Table 2

List of values used to generate HCSP emissions estimates for the three methods used in this paper and the resulting emissions for notable species.

\begin{tabular}{llll}
\hline Parameters & $E=\mathrm{FRE} * \mathrm{CF} * E F$ & $E=\mathrm{FRE} * E C$ & $E=\mathrm{FRE} * C_{e}$ \\
\hline FRE & & $14.5 \mathrm{e}+06 \mathrm{MJ}$ & \\
$\mathrm{CF}$ & $0.261 \mathrm{~kg} \mathrm{MJ}^{-1}$ & - & - \\
$E C$ & - & $0.0025 \mathrm{~kg} \mathrm{MJ}^{-1}$ & - \\
$C_{e}$ & - & $0.00612 \mathrm{~kg} \mathrm{MJ}^{-1}$ \\
Species $\left(E F \mathrm{~kg}^{-1}\right)^{\mathrm{a}}$ & & & \\
TPM $(8.3)$ & $3.1 \mathrm{e}+04 \mathrm{~kg}$ & $7.6 \mathrm{e}+04 \mathrm{~kg}$ & $8.9 \mathrm{e}+04 \mathrm{~kg}$ \\
$\mathrm{PM}_{2.5}(5.4)$ & $2.0 \mathrm{e}+04 \mathrm{~kg}$ & $5.0 \mathrm{e}+04 \mathrm{~kg}$ & $5.8 \mathrm{e}+04 \mathrm{~kg}$ \\
$\mathrm{TC}(3.7)$ & $1.4 \mathrm{e}+04 \mathrm{~kg}$ & $3.4 \mathrm{e}+04 \mathrm{~kg}$ & $3.9 \mathrm{e}+04 \mathrm{~kg}$ \\
$\mathrm{OC}(3.4)$ & $1.3 \mathrm{e}+04 \mathrm{~kg}$ & $3.1 \mathrm{e}+04 \mathrm{~kg}$ & $3.6 \mathrm{e}+04 \mathrm{~kg}$ \\
$\mathrm{BC}(0.48)$ & $1.8 \mathrm{e}+03 \mathrm{~kg}$ & $4.4 \mathrm{e}+03 \mathrm{~kg}$ & $5.1 \mathrm{e}+03 \mathrm{~kg}$ \\
$\mathrm{OCBC}$ & $1.5 \mathrm{e}+04 \mathrm{~kg}$ & $3.6 \mathrm{e}+04 \mathrm{~kg}$ & $4.1 \mathrm{e}+04 \mathrm{~kg}$ \\
$\mathrm{C}$ & $1.7 \mathrm{e}+06 \mathrm{~kg}$ & $4.0 \mathrm{e}+04 \mathrm{~kg}$ & $4.7 \mathrm{e}+06 \mathrm{~kg}$ \\
$\mathrm{CO}_{2}(1613)$ & $6.1 \mathrm{e}+06 \mathrm{~kg}$ & $14.8 \mathrm{e}+06 \mathrm{~kg}$ & $17.2 \mathrm{e}+06 \mathrm{~kg}$ \\
\hline
\end{tabular}

a Emission factors are from Andreae and Merlet (2001). OCBC was calculated as the sum of $\mathrm{OC}$ and $\mathrm{BC}$ emission. Carbon emission was calculated based on the fraction of $\mathrm{CO}_{2}$.
Agreement between airborne and spaceborne fire retrievals varied depending on satellite observation conditions. The development of a thick smoke plume overlapping part of the fire perimeter and surrounding areas resulted in omitted fire detections or characterization data in both Aqua/MODIS and GOES east and west imagery and consequent underestimation of FRP retrievals. Proper identification of omission errors followed by atmospheric correction of satellite and airborne radiance data proved useful in reducing differences between near-coincident fire retrievals.

Using a collection of FRP data points derived from airborne and spaceborne fire pixels, the total energy released (FRE) during approximately $7 \mathrm{~h}$ of flaming fire activity was estimated to be $14.5 \mathrm{e}+06 \mathrm{MJ}$. By applying the fuel consumption factor of $0.261 \mathrm{~kg} \mathrm{MJ}^{-1}$ derived from the in situ data, we estimated the total fuel consumption to be equivalent to $3.8 \mathrm{e}+06 \mathrm{~kg}$. If we were to apply the consumption factor of $0.368 \mathrm{~kg} \mathrm{MJ}^{-1}$ reported by Wooster et al. (2005), derived from a stationary fuel bed using primarily grass fuel (Miscanthus), our estimate of biomass consumed would increase by $34 \%$ to $5.3 \mathrm{e}+06 \mathrm{~kg}$. Emissions estimates were approached via two separate techniques $\left(E C_{O C B C}\right.$ and $\left.C_{e}\right)$ using the FRE estimate above. Results for various species showed a $15 \%$ difference. Use of instantaneous FRP retrievals in combination with other non-instantaneous retrievals such as AOD or plume injection height, which reflect the accumulated response of atmospheric conditions to minutes or hours of fire emissions or energy release, remains a main area for further research. In addition, the $34 \%$ increase in biomass consumed using a previously published consumption factor translated to the same increase in emissions reported in the second column of Table 2, highlighting the effect fuel types and conditions, as well as field methods, can have on deriving FRE-based combustion factors and ultimately emission results.

Our results served to highlight the value and quality of in situ and multi-spectral airborne remote sensing fire data for use in support of satellite fire retrieval analyses and emissions estimation. The selection of a prescribed fire for our study proved very useful and was possible because of smooth coordination between fire managers and science teams. The observed fire conditions resulted in some moderate to high flame intensity lasting for prolonged hours, extensive fire-affected area and significant smoke release, meeting with ample margin the minimum requirements to allow detection and characterization by different spaceborne sensors.

In order to improve upon the retrieval methods and error characterization involving both satellite fire products and emissions estimates presented in this study, future field experiments should expand on both ground and airborne sampling. For instance, due to 
time and resource constrains our in situ sampling was confined to a small subset of the burn plot where light fuels predominated. Our fine resolution airborne data and ground survey information showed that fire intensity was considerably higher in other parts of the perimeter where uphill flame propagation occurred over heavier fuel loads. Similarly, airborne data acquisition was limited to two relatively short intervals of $1 \mathrm{~h}$ each and included a non-negligible amount of pixel saturation. Greater flight endurance and higher sensor saturation temperature in the primary MWIR channel would enable a more complete and informative profile of the fire's lifespan including peak activity and later decay. Investigation of fine resolution burn severity using pre-, active- and post-fire sampling was limited by the available airborne data. Deployment of ground radiometers in the open field ensured sampling of the free-running fire front, but it also complicated coordination of aircraft overflights to ensure simultaneous ground and airborne sampling of fire radiative output. Hence, calibration of airborne fire retrievals would also benefit from a separate control plot consisting of a static fuel bed with which coincident ground and airborne sampling can be secured.

Finally, use of the data sets above showed great potential for fire management training and development, providing high quality data to help assess prescribed fire techniques and to address fuel treatment and individual fire emissions. Development of such refined fire sampling and inventorying techniques will prove valuable to further advance regional and global biomass burning emissions estimates.

\section{Acknowledgments}

We are grateful for all the support provided by the CAL FIRE Santa Clara Unit personnel and California State Parks Park staff, who implemented the prescribed fire at HCSP and supported in situ science data collection, the NASA/Dryden and NASA/Ames aircrew and system engineers responsible for the AMS system operation. Funding support for the airborne operations was provided by Dr. Diane Wickland through NASA's Terrestrial Ecology program office and additional funding support for science data analyses was provided by NASA's Earth Science grant NNX11AM26G. We also thank Shana Mattoo at NASA/Goddard for providing customized MODIS aerosol product files for improved emissions calculations.

\section{References}

Acker, J. G., \& Leptoukh, G. (2007). Online analysis enhances use of NASA Earth science data. EOS Transactions American Geophysical Union, 88(2), 14-17. http://dx.doi.org/10.1029/ 2007EO020003.

Àgueda, A., Pastor, E., Pérez, Y., \& Planas, E. (2010). Experimental study of the emissivity of flames 491 resulting from the combustion of forest fuels. International Journal of Thermal Sciences, 49, 543-554.

Ambrosia, V. G., \& Hinkley, E. (2008). NASA science serving society: Improving capabilities for fire characterization to effect reduction in disaster losses. Proceedings of the IEEE Geoscience and Remote Sensing Symposium, Vol. 4. http://dx.doi.org/10.1109/ IGARSS.2008.4779800.

Andreae, M.O., \& Merlet, P. (2001). Emission of trace gases and aerosols from biomass burning. Global Biogeochemical Cycles, 15(4), 955-966.

Berk, A., Anderson, G. P., Acharya, P. K., Hoke, M., Chetwynd, J., Bernstein, L., et al. (2003). MODTRAN4 version 3 revision 1 user's manual. Air Force Research Laboratory.

Crutzen, P. J., \& Andreae, M.O. (1990). Biomass burning in the tropics: Impact on atmospheric chemistry and biogeochemical cycles. Science, 250, 1669-1678.

DeBell, L. J., Talbot, R. W., Dibb, J. E., Munger, J. W., Fischer, E. V., \& Frolking, S. E. (2004) A major regional air pollution event in the northeastern United States caused by extensive forest fires in Quebec, Canada. Journal of Geophysical Research, 109(D19305). http://dx.doi.org/10.1029/2004JD004840.

Dozier, J. (1981). A method for satellite identification of surface temperature fields of subpixel resolution. Remote Sensing of Environment, 11, 221-229.

Ellicott, E., Vermote, E., Giglio, L., \& Roberts, G. (2009). Estimating biomass consumed from fires using MODIS FRE. Geophysical Research Letters, 36(L13401). http:// dx.doi.org/10.1029/2009GL038581.

Freeborn, P. H., Wooster, M. J., Hao, W. M., Ryan, C. A., Nordgren, B.L., Baker, S. P., et al (2008). Relationships between energy release, fuel mass loss, and trace gas and aerosol emissions during laboratory biomass fires. Journal of Geophysical Research, 113(D01301). http://dx.doi.org/10.1029/2007JD008679.

Giglio, L. (2007). Characterization of the tropical diurnal fire cycle using VIRS and MODIS observations. Remote Sensing of Environment, 108, 407-421.
Giglio, L., Descloitres, J., Justice, C. O., \& Kaufman, Y. J. (2003). An enhanced contextual fire detection algorithm for MODIS. Remote Sensing of Environment, 87, 273-282.

Giglio, L., \& Kendall, J. (2001). Application of the Dozier retrieval to wildfire characterization: A sensitivity analysis. Remote Sensing of Environment, 77, 34-49.

Hoffmann, W. A., Schroeder, W., \& Jackson, R. B. (2003). Regional feedbacks among, fire, climate, and tropical deforestation. Journal of Geophysical Research, 108(D23), 4721. http://dx.doi.org/10.1029/2003JD003494.

Ichoku, C., \& Ellison, L. (2013). Global top-down smoke aerosol emissions estimation using satellite fire radiative power measurements. Atmospheric Chemistry and Physics, 13, 27327-27386. http://dx.doi.org/10.5194/acpd-13-27327-2013.

Ichoku, C., Giglio, L., Wooster, M. J., \& Remer, L. A. (2008). Global characterization of biomass-burning patterns using satellite measurements of fire radiative energy. Remote Sensing of Environment, 112, 2,950-2,962

Ichoku, C., \& Kaufman, Y. J. (2005). A method to derive smoke emission rates from MODIS fire radiative energy measurements. IEEE Transactions on Geoscience and Remote Sensing, 43(11), 2636-2649. http://dx.doi.org/10.1109/Tgrs.2005.857328.

Ichoku, C., Martins, J. V., Kaufman, Y. J., Wooster, M. J., Freeborn, P. H., Hao, W. M., et al. (2008). Laboratory investigation of fire radiative energy and smoke aerosol emissions. Journal of Geophysical Research, 113(D14). http://dx.doi.org/10.1029/ 2007JD009659.

Jaffe, D., Bertschi, I., Jaeglé, L., Novelli, P., Reid, J. S., Tanimoto, H., et al. (2004). Long-range transport of Siberian biomass burning emissions and impact on surface ozone in Western North America. Geophysical Research Letters, 31(L16106). http://dx.doi.org 10.1029/2004GL020093.

Justice, C. O., Giglio, L., Korontzi, S., Owens, J., Morisette, J. T., Roy, D., et al. (2002). The MODIS fire products. Remote Sensing of Environment, 83, 244-262.

Kaiser, J. W., Heil, A., Andreae, M.O., Benedetti, A., Chubarova, N., Jones, L., et al. (2012) Biomass burning emissions estimated with a global fire assimilation system based on observed fire radiative power. Biogeosciences, 9, 527-554.

Kasischke, E. S., \& Penner, J. E. (2004). Improving global estimates of atmospheric emissions from biomass burning. Journal of Geophysical Research-Atmospheres, 109(D14s01). http://dx.doi.org/10.1029/2004jd004972.

Kaufman, Y. J., Justice, C. O., Flynn, L. P., Kendall, J.D., Prins, E. M., Giglio, L., et al. (1998) Potential global fire monitoring from EOS-MODIS. Journal of Geophysical Research, 103(D24), 32,215-32,238.

Kaufman, Y. J., Kleidman, R. G., \& King, M.D. (1998). SCAR-B fires in the tropics: Properties and remote sensing from EOS-MODIS. Journal of Geophysical Research, 103(D24) 31,955-31,968.

King, M.D., Platnick, S., Moeller, C. C., Revercomb, H. E., \& Chu, D. E. (2003). Remote sensing of smoke, land, and clouds from the NASA ER-2 during SAFARI 2000. Journal of Geophysical Atmospheres, 108(D13). http://dx.doi.org/10.1029/2002JD003207.

Korontzi, S., Roy, D. P., Justice, C. O., \& Ward, D. E. (2004). Modeling and sensitivity analysis of fire emissions in southern Africa during SAFARI 2000. Remote Sensing of Environment, 92, 376-396.

Kremens, R. L., Dickinson, M. B., \& Bova, A. S. (2012). Radiant flux density, energy density, and fuel consumption in mixed-oak forest surface fires. International Journal of Wildland Fire, 21, 722-730.

Levy, R. C., Remer, L. A., Tanré, D., Mattoo, S., \& Kaufman, Y. J. (2009). Algorithm for remote sensing of tropospheric aerosol over dark targets from MODIS: Collections 005 and 051 . revision 2, February 2009. MODIS Algorithm Theoretical Basis Document.

McKenzie, D., Gedalof, Z., Peterson, D. L., \& Mote, P. (2004). Climatic change, wildfire and conservation. Conservation Biology, 18(4), 890-902.

Moody, J. A., Martin, D. A., Haire, S. L., \& Kinner, D. A. (2007). Linking runoff response to burn severity after a wildfire. Hydrological Processes, 22(13), 2,063-2,074.

Oertel, D., Briess, K., Halle, W., Neidhardt, M., Lorenz, E., Sandau, R., et al. (2003). Airborne forest fire mapping with an adaptive infrared sensor. International Journal of Remote Sensing, 24(18), 3,663-3,682

Ononye, A. E., Vodacek, A., \& Saber, E. (2007). Automated extraction of fire line parameters from multispectral infrared images. Remote Sensing of Environment, 108(2), 179-188.

Pereira, G., Freitas, S. R., Moraes, E. C., Ferreira, N. J., Shimabukuro, Y. E., Rao, V. B. et al. (2009). Estimating trace gas and aerosol emissions over South America: Relationship between fire radiative energy released and aerosol optical depth observations. Atmospheric Environment, 43, 6,388-6,397.

Peterson, D., Wung, J., Ichoku, C., Hyer, E., \& Ambrosia, V. (2013). A sub-pixel-based calculation of fire radiative power from MODIS observations: 1 algorithm development and initial assessment. Remote Sensing of Environment, 129, 262-279.

Phillips, O. L., Aragão, L. E. O., Lewis, S. M., Fisher, J. B., Lloyd, J., López-Gonzalez, B., et al. (2009). Drought sensitivity of the Amazon rainforest. Science, 323(5919), 1,344-1,347.

Prins, E. M., \& Menzel, W. P. (1992). Geostationary satellite detection of biomass burning in South America. International Journal of Remote Sensing, 13, 2,783-2,799.

Remer, L. A., Kaufman, Y. J., Tanré, D., Mattoo, S., Chu, D. A., Martins, J. V., et al. (2005). The MODIS aerosol algorithm, products, and validation. Journal of the Atmospheric Sciences, 62(4), 947-973. http://dx.doi.org/10.1175/JAS3385.1.

Rienecker, M. M., Suarez, M. J., Todling, R., Bacmeister, J., Takacs, L., Liu, H. -C., Gu, W. Sienkiewicz, M., Koster, R. D., Gelaro, R., Stajner, I., \& Nielsen, J. E. (2008). In M. J. Suarez (Ed.), The GEOS-5 Data Assimilation System - documentation of versions 5.0.1 5.1.0, and 5.2.0, Vol. 27, National Aeronautics and Space Administration.

Riggan, P. J., Tissell, R. G., Lockwood, R. N., Brass, J. A., Pereira, J. A.R., Miranda, H., et al. (2004). Remote measurement of energy and carbon flux from wildfires in Brazil. Ecological Applications, 14(3), 855-872.

Schroeder, W., Csiszar, I., Giglio, L., \& Schmidt, C. C. (2010). On the use of fire radiative power, area, and temperature estimates to characterize biomass burning via moderate to coarse spatial resolution remote sensing data in the Brazilian Amazon. Journal of Geophysical Research, 115(D21121). http://dx.doi.org/ 10.1029/2009JD013769. 
Setzer, A. W., \& Verstraete, M. M. (1994). Fire and glint in AVHRR's channel 3: a possible reason for the non-saturation mystery. International Journal of Remote Sensing, 15(3), 711-718.

Vermote, E., Ellicott, E., Dubovik, O., Lapyonok, T., Chin, M., Giglio, L., et al. (2009). An approach to estimate global biomass burning emissions of organic and black carbon from MODIS fire radiative power. Journal of Geophysical Research, 114(D18205). http://dx.doi.org/10.1029/2008JD011188.

Westerling, A. L., Hidalgo, H. G., Cayan, D. R., \& Swetnam, T. W. (2006). Warming and earlier Spring increase Western U. S. forest wildfire activity. Science, 313(5789), 940-943.
Wooster, M. J., Roberts, G., \& Perry, G. L. W. (2005). Retrieval of biomass combustion rates and total from fire radiative power observations: FRP derivation and calibration relationships between biomass consumption and fire radiative energy release. Journal of Geophysical Research, 110(D24311). http://dx.doi.org/10.1029/2005JD006318.

Wooster, M. J., Zhukov, B., \& Oertel, D. (2003). Fire radiative energy for quantitative study of biomass burning: Derivation from the BIRD experimental satellite and comparison to MODIS products. Remote Sensing of Environment, 86, 83-107.

Xu, W., Wooster, M. J., Roberts, G., \& Freeborn, P. (2010). New GOES imager algorithms for cloud and active fire detection and fire radiative power assessment across North, South, and Central America. Remote Sensing of Environment, 114, 1,876-1,895. 